\title{
Printed Textbooks Versus Electronic Textbooks: A Study on the Preference of Students of Gulf University in Kingdom of Bahrain
}

\author{
https://doi.org/10.3991/ijet.v15i18.15217 \\ Mohanad Alfiras $\left({ }^{\bowtie}\right)$, Janaki Bojiah \\ Gulf University, Sanad, Bahrain \\ dr.mohanad.alfiraseGulfuniversity.edu.bh
}

\begin{abstract}
Technology has become an indispensable phenomenon in the contemporary era which has its impact in every walk of life and education is not an exception to this. The tech-savvy students of today have easily adopted the electronic textbooks as a replacement of printed textbooks owing to its ease of use, cost effectiveness and accessibility. Varied views on the students' preference of the specified format of textbooks have laid the platform for more formal and focused research pursuits these days globally. Therefore, a research to differentiate the advantages and disadvantages of both the formats and the reasons that are primary to opt for the one over the other at a regional level is very much the need of the hour. The study aimed to find out the interest and preference that prevailed in the minds of students of Gulf University, Kingdom of Bahrain, with respect to the adopting of electronic textbooks over the printed textbooks as this kind of study has been carried out much limited in this region. A list of questions was made in order to find out the pros and cons of the printed textbooks and electronic textbooks so that the valid reasons for the preference could be identified. The study adopted a quantitative research design and the questionnaire as a research tool to collect the data. The result affirms that most of the students are familiar with both the formats of textbooks and are more comfortable using electronic textbooks and have expressed their willingness to a complete shift from printed textbooks to electronic textbooks. Nevertheless, the findings make it clear that the students opt for electronic textbooks depending upon the nature of the subject or academic discipline.
\end{abstract}

Keywords - Printed textbook, electronic textbook, textbook preference, Gulf University.

\section{Introduction}

Cybernation has become an indispensable phenomenon of the contemporary era which has its impact on every field of civilization. As Weisburg [1] suggested that digital technology is used for "communication, socialization, entertainment and learning information," it has its significant role to play in the area of education as well. Karabatzaki [2] confirmed that use of technology has enriched student engagement 
drastically. In the opinion of Simon and Garcia-Belmar [3], the tech-savvy mentality of the contemporary students has welcomed the encroachment of innovative technologies into the teaching and learning process. Irrespective of the ages, the main purpose of education has always been to help students "become independent learners, able to inquire, understand, and analyze ideas and use their knowledge to solve problems," as defined by Dobler [4]. Ever since the beginning of ancient civilization, education has been changing its form owing to the societal shifts. Hence, in today's era, education is bound to infuse technology to make the teaching interesting and the learning experience not only just informative but also fascinating and fun-filled by using varied digital tools meant for education as affirmed by Dayakar [5] that "the eresources have become an inseparable part of the educational system." To add to this, Makwanya and Oni [6] asserted that, "Individuals are now used to producing, writing, storing and retrieving documents electronically on a wide range of electronic devices."

As the days progress, it has started its invasion into the textbook materials too as the students of today are considered by Reich et al. [7] to be "digital natives." Initially the digital technology has played a role in making the teaching methods to be more effective by providing audio-visual aids such as audio tracks, videos, live streaming etc. As Engbrecht [8] encapsulated that the teachers have been, "using more multimedia in their presentations and incorporating digital resources such as academic games and interactive websites into lesson plans." But, in course of time, it has evolved to be the pioneer to change from the printed textbooks to electronic textbooks which in the recent past has further developed to be interactive electronic textbooks. As Boticki et al. [9] affirmed that, "E-books have become a popular medium for content delivery and are being widely accepted as an alternative to traditional paper-based books." Muir and Hawes [10] discovered through their study that "electronic and print books can co-exist, and the growth of the former represents more of an opportunity than a threat." This confirmed the prediction offered by Lee, Messom and Yau [11] that the electronic textbooks, "will potentially replace existing paper-based textbooks." Hence, a thorough analysis to find out the preference of the students with respect to the preferred format of textbooks forms the background of this study.

Gulf University is a private university that offers Bachelor program in four academic specializations namely Interior Design Engineering, Administrative and Financial Sciences, Human Resource Management and Mass Communication. The key purpose of Gulf University is to impart outcome-based education through the state-ofthe-art infrastructure equipped with advanced technologies inculcating attributes of creativity and sustainability. The researchers in the university leave no stone unturned to find the ways and means to show continuous progression in enhancing the academic excellence. This study is fundamentally an attempt to clarify if there is a need to change the mode of textbooks for enriching the learning experience of the students. 


\section{$2 \quad$ Literature Review}

Traditional teaching and learning started with manuscript resources which later became the printed textbooks with the invention of printing press. In the words of Majid et al. [12], "Books are the most important medium for knowledge dissemination, personality development, and for leisure reading." As this printed form has been the only resource to get information in educational institutions since childhood, no wonder the whole generation of the early 20th century derived pleasure out of treasuring the textbooks, sharing the textbooks with others, highlighting, note-taking and scribbling on the textbooks when bored in classes. These constitute wonderful memories of that generation's study days. In addition, reselling of the printed textbooks as well as the touch and feel of them really contributed to its preference both by the educationists and users. The students' familiarity with the traditional printed textbooks as well as the comfort and ease of use of printed textbooks are the primary reasons for the students' preference of the same and this was confirmed by the study undertaken by Bouck, Weng, \& Satsangi [13]. Miller and Schrier [14] opined that the technologydriven students "may be accustomed to using technology, but they do not know, or are not taught, how to use it efficiently and effectively." Maybe these are the reasons for the preference of printed textbooks by the students even today as Millar and Schrier [14] observed thus, "Students also appreciate that with printed textbooks they can go back and look at their notes and highlighted sections of the book after a course has ended as some like to keep their textbooks. However, for e-textbooks, many are only available for a semester, after which time a student loses access to it." In addition, Mangen et al. [15] pointed out that, "Scrolling is known to hamper the process of reading, by imposing a spatial instability which may negatively affect the reader's mental representation of the text and, by implication, comprehension." Further, Cennamo, Ross, and Ertmer [16] expressed their concern that, "Computer monitors challenge our eyes in ways that printed text does not and may lead to vision problems."

According to Lokar [17], electronic textbooks could be reasonably cheaper than printed textbooks and according to Chulkov \& Van Alstine [18], the preference for the previous is based on "cost, ease of purchase, ability to keep the book, and match to their learning style." Nevertheless, Lee et al. [11] noted that the act of going digital also costs a lot. The cost comprises of purchase of smart devices, installation of software, maintenance of hardware, network infrastructure, additional accessories, internet usage, operational costs, upgrade and replacement costs, updating of anti-virus, and professional training. However, availability of a wide range of electronic devices at reasonable prices make it possible and affordable for people to own the smart devices according to Wiese \& du Plessis [19]. Asunka [20] opined that in the 1970s the electronic textbooks are just digitalised print books with no added technical features or interactive tools which was further confirmed by Choppin et al. [21]. Hence, these were not playing an impactful role in enhancing the learning experience of students or helping the teachers in enhancing the effectiveness of the adopted pedagogies. Instead of facilitating the teaching experience to be more comfortable, electronic textbooks gave a nightmare to teachers owing to the lack of training, incompatibility between resources and devices, poor receptivity, buffering due to intermittent flow of internet, 
eye strain, posture problems, information overload and user resistance - hampering the smooth running of classes with electronic textbooks. However, the more practical and functional electronic textbooks have evolved in 2009 as stated by Weisberg [1], who acknowledged that they "offered little more than straightforward reading capabilities." In 2010, this version was further developed with a few more added features on the smart devices such as, "basic note taking, highlighting, and search capabilities," as confirmed by Weisberg [1]. However, the study conducted by Mizrachi et al. [22] found out that the students preferred to print out for highlighting rather than using digital features. Muir and Hawes [10] discovered that the students need upgraded interface to enhance the learning experience and according to Baker-Eveleth and Stone [23], the students access electronic textbooks to view, "content on a website, a PDF download, or on an electronic reading device." Almost all the electronic textbooks come in a PDF format as it is considered to be more user-friendly and nearly "all computers and other digital computing devices such as smart phones and tablets have software that will render PDF files without compromising the original formatting," as confirmed by Feldstein et al. [24]. Thanks to the technological advancements, there has been an evolution and in course of time the upgraded electronic textbooks have gained momentum owing to features namely, "still and moving graphics, and video clips, as well as the potential to add supportive materials such as audio collections, links to activities and websites etc.," as studied by Woody, Daniel, and Baker [25] acknowledging the opinion of Heider, Laverick, and Bennett [26] that electronic textbooks have the potential to "offer students a more personalized, interactive multimedia experience." As defined by Rockinson-Szapkiw et al. [27], these interactive electronic books supported student engagement not only inside the classroom but also outside the classroom which confirmed the idea of Mulholland \& Bates [28] that the electronic textbooks are in an atmosphere that is "rapidly and constantly evolving." This was further acknowledged by Sung et al. [29] thus, "the interactive ebook learning mode can trigger learners' deep motive, and hence promote their learning achievement." According to the study conducted by Rowlands et al. [30], the students tend to adopt electronic textbooks as they consider them to be updated, all time accessible, not space consuming and user-friendly. They believe that technology driven classes are more interesting as these really play a significant role in enhancing the teaching and learning experience as confirmed by Rockinson-Szapkiw [27]. Nevertheless, the students find problems regarding the readability, highlighting as well as bookmarking and the way the teachers embed technology in class also matters in the preferred choice made by the students. Chulkov and VanAlstine [18] argued that the choice of the printed or electronic textbooks is highly influenced by the learning habits of the students. Technology equips us with smart tools to bring in a vivid classroom experience as confirmed by Merzifonluoglu [31]. However, it is the responsibility of teachers to opt for the right materials to impart the specified topic to the class with a defined frame of reference. Further, Okert [32] asserted that "Several research studies on the use of technology in the classroom have shown a positive impact on the motivation of learners..." In this regard, Beetham and Sharepe [33] pinpointed that, "It is arguable that there is no need for a theory of technology-enhanced learning. Technology can play an important role in the achievement of learning outcomes, but it 
seems unnecessary to explain this enhancement with a special account of learning. Rather, the challenge is to describe how the technology allows underlying process common to all learning to function effectively." Hence, it becomes inevitable to find out from the various sources the effectiveness of usage of electronic textbooks and whether the effective use is variable to the kind of academic discipline chosen. The findings of the study would lay a scope for the complete adoption of electronic textbooks by the university or maintaining the current trend of mix of printed and electronic textbooks.

\section{$3 \quad$ Research Methodology}

\subsection{Research design}

In this research, a quantitative methodology was used in order to examine the respondents' responses more objectively and to permit greater assessment. According to the objective of the study, the questionnaire was designed and modified. In designing the question items, the researchers adopted and modified the question pattern from previous researchers to suit the current research. Data collection was made using an online survey where the students were voluntarily invited from all the academic disciplines offered in Gulf University. The sample size $(\mathrm{N}=312)$ provided enough statistical power for the analysis to be performed on the data.

\subsection{Data analysis}

Statistical Package for Social Sciences (SPSS) version 20.0 version was used for data analysis. This study adopted a cross-sectional design and the data were collected from students studying in Gulf University using the questionnaire. The questionnaire employed to measure the concepts of demographic information such as (age, gender, level of study and awareness) and the concept perceptions and preference on electronic books and printed books. The data entailed descriptive.

\section{$4 \quad$ Findings}

A total of 312 students (Female: 180 and Male: 132) of Gulf University belonging to various academic disciplines responded to the questionnaire out of which the significant $52.2 \%$ are in the age group of $17-22$ years and $32.4 \%$ in the age group of 23 28 years. The data in detail are given in Figure 1: 


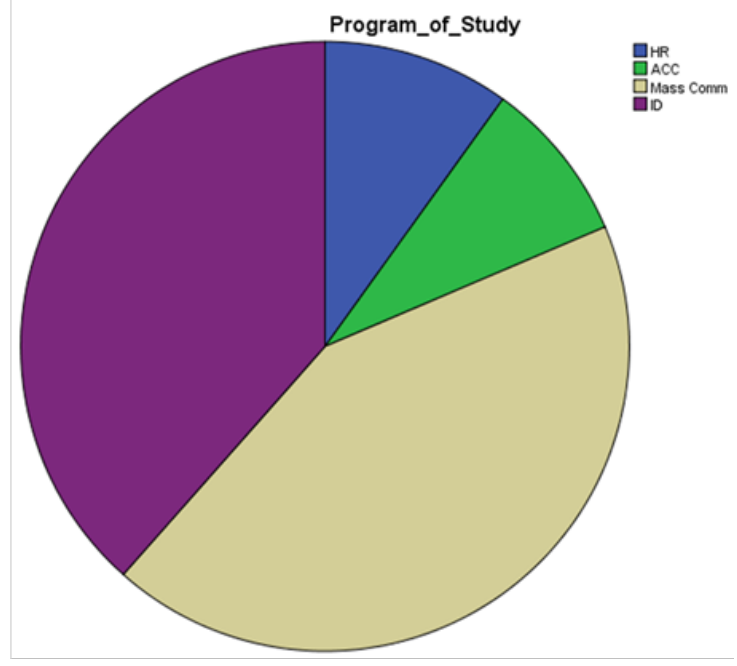

Fig. 1. No of students in the program of study at Gulf university

Table 1. Respondents and their Program of Study

\begin{tabular}{|c|l|c|c|c|c|}
\hline \multicolumn{2}{|c|}{ Program } & Frequency & Percent & Valid Percent & Cumulative Percent \\
\hline \multirow{5}{*}{ Valid } & HR & 31 & 9.9 & 9.9 & 9.9 \\
\cline { 2 - 6 } & ACC & 27 & 8.7 & 8.7 & 18.6 \\
\cline { 2 - 6 } & Mass Comm & 134 & 42.9 & 42.9 & 61.5 \\
\cline { 2 - 6 } & ID & 120 & 38.5 & 38.5 & 100.0 \\
\cline { 2 - 6 } & Total & 312 & 100.0 & 100.0 & \\
\hline
\end{tabular}

Printed textbooks: Students' perspectives: $41.3 \%$ of the respondents mentioned that they had sometimes used the printed textbooks, $21.4 \%$ mentioned that they had been using printed textbooks regularly, $17.9 \%$ mentioned that they used the printed textbooks only during the classes and $19.2 \%$ mentioned that had never used the printed textbooks at all. The responses make it very clear that the printed textbooks are losing its importance amidst the students as the students of today tend to resort to the notes taken in the classes, abstracts from the recent research studies and other online resources for the knowledge acquisition. The numbers of students using printed textbooks regularly and only during classes are gradually going down. When probed further, the respondents listed the following as the drawbacks of printed textbooks:

Table 2. Number the following four drawbacks as per your preference of printed textbooks?

\begin{tabular}{|l|c|c|c|c|}
\hline & First Choice & Second Choice & Third Choice & Fourth Choice \\
\hline Heavy to carry & $41 \%$ & $30 \%$ & $12.7 \%$ & $16.3 \%$ \\
\hline Consume more space & $20.3 \%$ & $35.3 \%$ & $35.4 \%$ & $9 \%$ \\
\hline Need specific lighting & $27.8 \%$ & $12.7 \%$ & $17.7 \%$ & $41.8 \%$ \\
\hline Costly & $10 \%$ & $22 \%$ & $35 \%$ & $33 \%$ \\
\hline
\end{tabular}

The reasons for the preference of printed books are as follows: 
Table 3. What do you like the most about the printed textbooks?

\begin{tabular}{|l|c|c|c|c|}
\hline & Frequency & Percent & Valid Percent & Cumulative Percent \\
\hline Loaned or Borrowed & 48 & 15.4 & 15.4 & 15.4 \\
\hline Touch and Feel & 48 & 15.4 & 15.4 & 30.8 \\
\hline Portable & 132 & 42.3 & 42.3 & 73.1 \\
\hline Highlighting and taking notes & 56 & 17.9 & 17.9 & 91.0 \\
\hline None of the Above & 28 & 9.0 & 9.0 & 100.0 \\
\hline Total & 312 & 100.0 & 100.0 & \\
\hline
\end{tabular}

The responses make it very clear that the students preferred printed textbook for its portability and availability for highlighting as well as taking notes which are in alignment with the findings of Banik et al. [34], Johnston \& Salaz [35], Khalid [36], and Piramanayagam \& Seal [37]. To support this, the study conducted by Johnston \& Ferguson [38] found out that the students hardly preferred to use highlighting digital features while dealing with the electronic textbooks.

Electronic textbooks: students' perspectives: $30.8 \%$ of the respondents mentioned that they had sometimes used the electronic textbooks, $28.2 \%$ mentioned that they had been using electronic textbooks regularly, 31.7\% mentioned that they used the electronic textbooks only during the classes and $9.3 \%$ mentioned that had never used the electronic textbooks at all. The responses make it very clear that the electronic textbooks are gaining its momentum amidst the students which is in alignment with the findings of Hendricks [39] and Leonard \& Snyman [40] because the students of today find it easier to access the online materials owing to the smart devices and highspeed internet that are available to them at a reasonable price. The reasons for the preference of electronic textbooks are as follows:

Table 4. What do you like about electronic textbooks?

\begin{tabular}{|l|c|c|c|c|}
\hline & Frequency & Percent & Valid Percent & Cumulative Percent \\
\hline Speedy and Easy Access & 151 & 48.4 & 48.4 & 48.4 \\
\hline Cost Effective & 43 & 13.8 & 13.8 & 62.2 \\
\hline No Space Consumption & 48 & 15.4 & 15.4 & 77.6 \\
\hline Ease of Archiving & 33 & 10.6 & 10.6 & 88.1 \\
\hline None of the above & 37 & 11.9 & 11.9 & 100.0 \\
\hline Total & 312 & 100.0 & 100.0 & \\
\hline
\end{tabular}

Though the reasons for the preference were in tune with the findings of research studies of Abram [41], Dillon [42], Shelburne [43] and Sun et al. [44], the students were equally aware of the drawbacks of the electronic textbooks as their awareness is clearly noted in the responses available in the table 5 . 
Table 5. Number the following four drawbacks as per your preference of electronic textbooks?

\begin{tabular}{|l|c|c|c|c|}
\hline & First Choice & Second Choice & Third Choice & Fourth Choice \\
\hline Dependent on devices & $40.5 \%$ & $44.3 \%$ & $3.8 \%$ & $11.4 \%$ \\
\hline Not good for prolonged reading & $46.8 \%$ & $16.5 \%$ & $24 \%$ & $12.7 \%$ \\
\hline Posture problems & $5 \%$ & $31.5 \%$ & $34.5 \%$ & $29 \%$ \\
\hline Adaptability issues & $7.6 \%$ & $7.6 \%$ & $38 \%$ & $46.4 \%$ \\
\hline
\end{tabular}

In addition, as Shin [45] pointed out that "When students find valuable information, they want it stored on their personal computer or in a computer network to secure its permanency. They do not consider an e-book as a permanent place to store valuable information," the students could not rely on electronic textbooks for an immediate retrieval of stored information. However, the findings of Wang [46] and Adeyinka et al. [47] suggested that the proportion of use of the electronic resources was more than that of the printed books.

Textbooks: Printed or electronic: $51.9 \%$ of respondents mentioned that they would prefer electronic textbooks whereas $48.1 \%$ mentioned that they would continue with the printed textbooks. It is note-worthy to realize that the findings of the study were contrary to the findings of the study carried out by Abuloum et al. [48] in University of Bahrain where the students were still expressing their interest to go for printed books over the electronic textbooks. In the current study, when the question was raised as to for what kind of subjects or academic disciplines, they would prefer having electronic textbooks, the responses state thus:

Table 6. What kind of subjects you would prefer electronic textbooks?

\begin{tabular}{|l|c|c|c|c|}
\hline & Frequency & Percent & Valid Percent & Cumulative Percent \\
\hline Languages & 86 & 27.6 & 27.6 & 27.6 \\
\hline Mathematics \& Engineering & 71 & 22.8 & 22.8 & 50.3 \\
\hline Social Sciences \& Management Studies & 130 & 41.7 & 41.7 & 92.0 \\
\hline Sciences & 25 & 8.0 & 8.0 & 100.0 \\
\hline Total & 312 & 100.0 & 100.0 & \\
\hline
\end{tabular}

The respondents suggested that electronic textbooks are the best for academic disciplines like social sciences, management studies and languages in the order of preference. This may be due to highly theoretical nature of the courses pertaining to these academic disciplines. $22.8 \%$ suggested that electronic textbooks could be preferred for imparting mathematics and engineering disciplines whereas less than $10 \%$ suggested that electronic textbooks could be suitable for science discipline. This calls for an attention that the developers of electronic textbooks and other online resources should pay more attention in designing the electronic textbooks pertaining to science discipline in order to facilitate students. 


\section{Discussion}

This study intended to identify the reasons behind the preferred mode of textbooks in Gulf University students and many such research studies have been carried out globally. The study surveyed a sample of 312 students from various academic disciplines namely Interior Design Engineering, Administrative and Financial Sciences, Human Resource Management and Mass Communication. In the sample, it was worthy to note that a greater number of female students than male students participated though the sampling was drawn at random. All the students participated in the online survey were experienced in using textbooks for their studies in both printed and electronic formats. The findings stated that they would prefer to opt for electronic textbooks altogether.

In addition, the participants were aware of the necessity of the smart devices and varied formats of electronic textbooks. Further, they possessed the advanced knowledge of the latest interactive tools available on electronic textbooks and the thorough awareness of the need for high speed internet for the knowledge transmission through electronic textbooks. Since the students had the experience of handling both the formats of textbooks, the findings of this study become more authentic. In addition, the respondents possessed the knowledge to compare the effective knowledge transfer of varied subjects too.

\section{Conclusion}

This study identified the reasons behind the students' preference of printed or electronic versions of textbooks only taking into consideration the current students of Gulf University. Hence, it lays the scope to extend the study for the entire university student population of the whole country or the region for a more concrete result. Longitudinal research should be initiated in future to decide on the complete adoption of electronic textbooks in the higher educational institutes. Comparing the trend with other countries can also facilitate more interpretations in this regard. Despite the repeated researches in various parts of the globe, the question of making printed or traditional textbooks completely dispensable is still unanswered. However, the changing trend of modernization and evolution of technology on a day-to-day basis may lead to complete switch over from printed textbooks to electronic textbooks.

\section{Acknowledgement}

You may mention here granted financial support or acknowledge the help you got from others during your research work. 


\section{References}

[1] Weisberg, M. (2011). Student attitudes and behaviors towards digital textbooks. Publishing Research Quarterly, 27(2), 188-196. https://doi.org/10.1007/s12109-011-9217-4

[2] Karabatzaki, Z., Stathopoulou, A., Kokkalia, G., Dimitriou, E., Loukeri, P., Economou, A. \& Drigas, A. (2018). Mobile application tools for students in secondary education: An evaluation study. International Journal of Interactive Mobile Technologies, 12(2), 142-161. https://doi.org/10.3991/ijim.v12i2.8158.

[3] Simon, J., \& Garcia-Belmar, A. (2016). Education and textbooks. Technology and Culture, 57(4), 940-950. https://doi.org/10.1353/tech.2016.0114

[4] Dobler, E. (2015). E-textbooks. Journal of Adolescent \& Adult Literacy, 58(6), 482-491. https://doi.org/10.1002/jaal.391

[5] Dayakar, G. (2018). Use of e-resources in higher education: Advantages and concerns. Journal of Applied and Advanced Research, 3(1), S17-S19. Phoenix Research Publishers. https://doi.org/10.21839/jaar.2018.v3is1.160

[6] Makwanya, C., \& Oni, O. (2019). E-books preference compared to print books based on student perceptions: A case on University of Fort Hare students. International Journal of Interactive Mobile Technologies, 13(12), 236-245. https://doi.org/10.3991/ijim.v13i12.108 $\underline{40}$

[7] Reich, S. M., Yau, J.C., Xu, Y., Muskat, T., Uvalle, J., \& Cannata, D. (2019). Digital or Print? A comparison of preschoolers' comprehension, vocabulary, and engagement from a print book and an e-book, 5(3), 1-16. https://doi.org/10.1177/2332858419878389

[8] Engbrecht, J. R. (2018). Digital textbooks versus print textbooks. Culminating Projects in Teacher Development. 35. https://repository.stcloudstate.edu/ed_etds/35.

[9] Boticki, I., Akçapınar, G., \& Ogata. H. (2019). E-book user modelling through learning analytics: The case of learner engagement and reading styles. Interactive Learning Environments, 27(5-6), 754-765. https://doi.org/10.1080/10494820.2019.1610459.

[10] Muir, L., \& Hawes, G. (2013). The case for e-book literacy: Undergraduate students' experience with e-books for course work. The Journal of Academic Librarianship, 39, 260-274. https://doi.org/10.1016/j.acalib.2013.01.002.

[11] Lee, H. J., Messom, C., \& Yau, K. A. (2013). Can an electronic textbook be part of K-12 education? Challenges, technological solutions and open issues. Turkish Online Journal of Educational Technology, 12(1), 32-44.

[12] Majid, S., Chenqin, Y., Chang,Y., \& Zilu, C. (2019). Perceptions and e-book use behavior of university students. International Journal of Digital Society, 10 (4), 1534-1540. https:// doi.org/10.20533/ijds.2040.2570.2019.0190

[13] Bouck, E. C., Weng, P., \& Satsangi, R. (2016). Digital versus traditional: Secondary students with visual impairments' perceptions of a digital algebra textbook. Journal of Visual Impairment \& Blindness, 110(1), 41-52. https://doi.org/10.1177/0145482x1611000105

[14] Millar, M., \& Schrier, T. (2015). Digital or printed textbooks: Which do students prefer and why? Journal of Teaching in Travel \& Tourism, 15(2), 166-185. https://doi.org/10.10 $\underline{80 / 15313220.2015 .1026474}$

[15] Mangen, A., Walgermo, B. R., \& Brønnick, K. (2013). Reading linear texts on paper versus computer screen: Effects on reading comprehension. International Journal of Educational Research, 58, 61-68. https://doi.org/10.1016/j.ijer.2012.12.002.

[16] Cennamo, K. S., Ross, J. D., \& Ertmer, P. A. (2014). Technology integration for meaningful classroom use: A standards-based approach. Belmont, CA: Wadsworth, Cengage Learning. 
[17] Lokar, M. (2015). The future of e-textbooks. International Journal for Technology in Mathematics Education, 22(3), 101-106. https://doi:10.1564/tme_v22.3.02

[18] Chulkov, D. V., \& VanAlstine, J. (2013). College student choice among electronic and printed textbook options. Journal of Education for Business, 88(4), 216-222. https://doi. org $/ 10.1080 / 08832323.2012 .672936$

[19] Wiese, M., \& du Plessis, G. (2014). The battle of the e-textbook: Libraries' role in facilitating student acceptance and use of e-textbooks. South African Journal of Libraries \& Information Science, 80(2), 17-26. https://doi.org/10.7553/80-2-1509.

[20] Asunka, S. (2013). The viability of e-textbooks in developing countries: Ghanaian University students' perceptions. Open Learning, 28(1), 36-50. https://doi:10.1080/02680513.201 $\underline{3.796285}$

[21] Choppin, J., Carson, C., Borys, Z., Cerosaletti, C., \& Gillis, R. (2014). A typology for analyzing digital curricula in mathematics education. International Journal of Education in Mathematics, Science and Technology, 2(1), 11-25. https://www.learntechlib. org/p/157732/. https://doi.org/10.18404/ijemst.95334

[22] Mizrachi, D., Salaz, A. M., Kurbanoglu, S., \& Boustany, J. (2018). Academic reading format preferences and behaviors among university students worldwide: A comparative survey analysis. PloS One, 13(5), e0197444. https://doi.org/10.1371/journal.pone.0197444.

[23] Baker-Eveleth, L. \& Stone, R. (2015). Usability, expectation, confirmation, and continuance intentions to use electronic textbooks. Behaviour \& Information Technology, 34(10), 992-1004. https://doi.org/10.1080/0144929X.2015.1039061

[24] Feldstein, A., Martin, M., Hudson, A., Warren, K., Hilton, J., III, \& Wiley, D. (2012). Open textbooks and increased student access and outcomes. European Journal of Open, Distance and E-Learning, (2), 1-9

[25] Woody, W., Daniel, U., and Baker, C. (2010). E-books or textbooks: Students prefer textbooks. Computer Education, 55, 945-948. https://doi.org/10.1016/j.compedu.2010.04.005

[26] Heider, K., Laverick, D., \& Bennett, B. (2009). Digital textbooks: The next paradigm shift in higher education? AACE Journal, 17(2), 103-112.

[27] Rockinson-Szapkiw, A. J., Courduff, J., Carter, K., \& Bennett, D. (2013). Electronic versus traditional print textbooks: A comparison study on the influence of university students' learning. Computers \& Education, 63, 259-266. https://doi.org/10.1016/j.compedu.2012. $\underline{11.022}$

[28] Mulholland, E., \& Bates, J. (2014). Use and perceptions of E-books by academic staff in further education. Journal of Academic Librarianship, 40(5), 492-499. https://doi.org/10.10 16/j.acalib.2014.05.018

[29] Sung H. Y., Hwang, G. J., Chen. C. Y., \& Liu. W. X. (2019). A contextual learning model for developing interactive e-books to improve students' performances of learning the Analects of Confucius. Interactive Learning Environments, 1-14. https://doi.org/10.1080/1049 4820.2019.1664595.

[30] Rowlands, I., Nicholas, D., Jamali, H.R. and Huntington, P. (2007). What do faculty and students really think about e-books. Aslib Proceedings, 59(6), 489-511. https://doi.org/10. $\underline{1108 / 00012530710839588}$

[31] Merzifonluoglu, A. \& Gonulal, A. (2018). Review of digital language learning and teaching: Research, theory and practice. Language Learning \& Technology. 22(1), 65-68.

[32] Oxkert, D. (2018). Using a tablet computer for EFL positive self-review: Increase in selfdetermination theory-based learning motives. Calido Journal. 35(2), 1-18. https://doi.org/1 $\underline{0.1558 / \text { cj. } 32185}$ 
[33] Beetham, H. \& Sharpe, R. (2013). Rethinking Pedagogy for a Digital Age: Designing for 21st Century Learning (2nd Edition). Florence, KY, USA: Routledge, 2013. ProQuest ebrary.

[34] Banik, P., Haque, M.A., Sultana, P., \& Kobir, M. R. (2019). E-book culture at Rajshahi University students in Bangladesh. International and Public Affairs, 3(2), 52-57. DOI: 10.11648/j.ipa.20190302.13.

[35] Johnston, N., \& Salaz, A. M. (2019). Exploring the reasons why university students prefer print over digital texts: An Australian perspective. Journal of the Australian Library and Information Association, 68(2), 126-145. https://doi.org/10.1080/24750158.2019.158785 8 .

[36] Khalid, A. (2014). Textbooks: e-book vs. print. Journal of Education and Human Development, 3(2), 243-258.

[37] Piramanayagam, S., \& Seal, P.P. (2020). The choice between e-books and printed books: A study among hospitality and tourism educators and learners. ProQuest.

[38] Johnston, N. \& Ferguson, N. (2020). University students' engagement with textbooks in print and e-book formats. Technical Services Quarterly, 37(1), 24-43. https://doi.org/10.10 80/07317131.2019.1691760.

[39] Hendricks, D. (2017). Why Digital Publishing is the Future of Education. Inc.com. Available at: https://www.inc.com/drew-hendricks/why-digital-publishing-is-the-future-ofeducat ion.html

[40] Leonard, A., \& Snyman, M. (2019). E-books: yes or no? A case study of undergraduate students at the University of Namibia. Emerald Publishing Limited, 38(3), 78-88. https:// doi.org/10.1108/cc-08-2018-0018

[41] Abram, S. (2010). P-books vs e-books: death match? Information Outlook, 14(6), 30-32.

[42] Dillon, D. (2001). E-books: The University of Texas experience, part 2. Library Hi Tech Journal, 19(4), 350-362. https://doi.org/10.1108/EUM0000000006540

[43] Shelburne, W. (2009). E-book usage in an academic library: User attitudes and behaviors. Library Collections, Acquisitions, \& Technical Services, 33(2-3), 59-72. https://doi.org/10. 1080/14649055.2009.10766234

[44] Sun, J., Flores, J., \& Tanguma, J. (2012). E-textbooks and students' learning experiences. Decision Sciences Journal of Innovative Education, 10(1), 63-77. https://doi.org/10.1111/j. 1540-4609.2011.00329.x

[45] Shin, S. (2014). E-book usability in educational technology classes: Teachers and teacher candidates' perception toward e-book for teaching and learning. International Journal of Distance Education Technologies, 12(3), 62-74. https://doi.org/10.4018/ijdet.20140701059 $\underline{6}$

[46] Wang, J. (2018). Retrieving critical design factor of ebook for older people in Taiwan. Telematics and Informatics, 35(7), 2016-2027. https://doi.org/10.1016/j.tele.2018.07.005

[47] Adeyinka, T., Dare, O., Adebisi, O., \& Lawal, A. (2018). Perception and usage pattern of e-books among library and information science students in selected universities in Nigeria. Journal of Library and Information Technology, 38(2), 132-140. http://doi.org/10.14429/dj lit.38.2.11111

[48] Abuloum, A., Farah. A., Kaskaloglu, E., \& Yaakub, A. (2019). College students' usage of and preferences for print and electronic textbooks. International Journal of Emerging Technologies in Learning, 14(7), 80-97. https://doi.org/10.3991/ijet.v14i07.9871 


\section{Authors}

Mohanned Alfiras received his B.Sc. Honors degree in Electric and Electronic Engineering in 1998 from University of Technology, Iraq. He continued his higher education at the same University and accomplished his MS. and Ph.D. degrees in Communication System Engineering in 2000 and 2006, respectively. In 2006, he joined Gulf University as an Assistant Professor in the Department of Computer Communication Engineering. He was promoted as the Head of Computer Communication Engineering in 2008. Mohanned Al Firas has authored/co-authored over 41 research/publications in peer reviewed reputed journals and presented papers in numerous conferences. With his academic accomplishments, he also continued his academic administrative duties at Gulf University. He fulfilled his duty as the Dean of Admissions and Registration of Gulf University. Since 2015, he had been extending his duty as the Acting President of Gulf University and from 2017 he has become the President of Gulf University.

Janaki Bojiah teaches English at Gulf University, Kingdom of Bahrain. She has nearly 20 research publications to her credit. She has the experience of participating in and organizing seminars and conferences.

Article submitted 2020-04-26. Resubmitted 2020-05-25. Final acceptance 2020-05-28. Final version published as submitted by the authors. 